\title{
MANFAAT PEMBINAAN BAGI NARAPIDANA SAAT MENJALANI PIDANA PENJARA
}

\author{
Petrus Irwan Panjaitan \\ I Dewa Ayu Widyani \\ petrus.pandjaitan@yahoo.com \\ Universitas Kristen Indonesia, Jakarta, Indonesia
}

\begin{abstract}
Consumer nancing business in the form of Credit Card as a form of less cash society is developing in Indonesia has even become a culture in modern society coupled with the support of fast payment system, safe, ef cient and reliable, smoothness in payment, providing legal certainty for the community in doing transaction, but consumer nance business though very attractive but does not mean this business has no risk at all, as credit giving, the risk will still exist at the time of stalled payment of credit card arrears by consumers. In the event of a consumer credit crunch, banks usually use debt collection services known as debt collectors. Often debt collectors in doing debt collection services work unprofessionally even sometimes tend to do acts against the law, so it will cause harm to customers and credit card issuing bank, because it is not in accordance with what is expected.
\end{abstract}

Keywords: payment system; Credit Card; debt collectors; accordance.

\section{Pendahuluan}

Kenyataan yang paling mendasar tentang penjara bagi tiap narapidana sesungguhnya adalah hilangnya kebebasan. Dalam arti yang berbeda-beda; tidak dapat makanan yang kita inginkan tidak dapat berpakaian semaunya tidak dapat mengadakan hubungan sex dan di atas semuanya itu kita tidak dapat bergerak, Kehilangan kebebasan berarti melepaskan diri dari tanggung jawab terhadap hidup. Segala sesuatu dilakukan untuk petugas, pembina, atau kepenting an lembaga, segala keputrusan mengenai kebutuhan narapidana dikendalikan. Sama sekali tidak berdaya dan menurut kewenangan orang lain. Kehilangan kebebasan didalam penjara berarti diatur; makan pada waktu tertentu: bangun pada saat tertentu: disekap pada waktu tertentu: dikunjungi keluarga pada saat tertentu pula. Para narapidana diingatkan pada hilangnva suatu kebebasan. dan kesadaran terhadap penaklukan dirinya menjadi cara berpikir yang utama dalatn hidupnya.

Masalah kebebasan bagi narapidan mpa-mpanya teiah menjadi sesuatu yang begitu penting, sentral dan berarti bagi hidupnya; seperti apa yang menjadi pengakuan seorang narapidana di bawah ini:

Freedom is the only meaningful things to a human without freedom things lose meaning. The whole system hiprisonis designed to degerated a human being, to break himas a man. The take awayall of his freedom to express himself and his feeling. How can't express yourself? The Lndenteiminate sentense gives the authorities tremendous control over a man's freedom: you are at their mercy and are really impotent to do anything about it (ablack prisoner, early thirties). ${ }^{1}$

Kebebasan adalah satu-satunya hal yang berarti bagi manusia, tanpa kebebasan adalah sia-sia seluruh sistem dalam penjara telah dirancang untuk menurunkan derajat mannsia, mematahkan semangatnya sebagai manusia. Mereka merampas seluruh kebebasannya untuk mengekpresikan drri kita sendrri? Putusan pengadilan yang tidak menentu memberi kekuasoan penuh bagi para penguasa untuk menentukan kebebasan seseorang; tergantung pada belas kasihaii mereka dan betul-betul tidak berdaya. (Seorang narapidana kulit hitam, berusia.30 tahun). (Terjemahan).

Kurun waktu yang begitu lama selama berada di lembaga pema-syarakatan. sebagai konsekuensi dari

\footnotetext{
1 Eric Olin Wright, The Meaning of Prison in the livers of prison dalam Criminal Justice Allies and Adversaries, John R. Snortum/ Illaiia Hader, palisades publisher. 1978. Hal. 183.
} 
masa Jmkuman yang harus dijalani terasa menyesakkan manakala narapidana harus menghitung-hitung harinya tanpa kegiatan. itulah sebabnya pemerintah Belanda dahulu menerapkan pidana penjara di Indonesia dengan berbagai bentuk kegiatan. (baik itu pembinaan fisik, kegiatan bekerja ketrampilan di bengkel kerja lebih kurang delapan sampai sembilan jam setiap harinya). Kegiatan ini, tentunya : mempunyai maksud dan tujuan tertentu, terlepas dari sasaran yang hendak dicapai maupun manusiawi tidaknya perlakukan tersebut, yang jelas di situ terkandung m'at agar pesakitan tidak mengingat penderitaan yang dialami dan .syukui-syukur kalaulahkegiatan itu dapat menimbulkan rasa percaya diri, bertobat. dan pada akhirnra menjadi taat pada nonna-nonna yang berlaku dalam masyarakat. Metoaliami hal di atas, sangat mudah dipaliami bahwa piinsip pembinaar. dl kala itu telah menunjukkan warna sempuma. Menyadari keberadaan pembinaan sebagai salab. satii metode yang efektif unruk menanamkan rasa percaya diri serta merubah perilaku menyimpang. rnaka selalu disoroti beatuk pembinaan bagaimanakah yang paling relevan dan manusiawi bagi pelanggar hukum selama menjalani hukuman.

Harus disadari baliwa narapidana yang berada di penjara merupakan masyarakat yang memiliki karakteristik penyimpangan perilaku yang berbeda. Di dalam penjara itu pula terjadi sosialisasi, di mana masyarakatnya berbeda dengan masyarakat luar, seperti apa yang disaksikan oleh Stanton Wheeler dalam salah satu tulisan yang berjudul: Socialization in correctional, lebih lanjut dikatakannya:

Cle.mm.er was a sociologist with many years/of experience behind the walls of prisons and the produced the first book-length study of piison as a community: Clemmer described the culture and social organization of the prison and noted that most of the characteristic he found suggested a system distinctly harmful to anyithing that might norms and codes a process of rehabilitation: the organized inopposition to those of conventional society. ${ }^{2}$ (Clemmer adalah seorang ahli sosiologi

2 Staton Wheeler, "Socialization in Correctional Institutions" dalam "Crime and Justice, edited by Sir Leon Randzinovics and Marvin E Wolfgang, New York: Basic Books, Inc, Publisher, 1969, Volume II, hal. 194 yang telah berpengalaman selama bertahun-tahun dibalik dinding penjara dan dia menulis penelitian pertama yang dibukukan mengenai penjara sebagai masyarakat. Clemmer menggambarkan kultur dan organisasi sosial dari penjara dan mencatat bahwa kebatiyakan ciri-ciri yang dia temukan menunjukkan suatu sistem yang jelas merasak terhadap segala sesuatu yang bisa dipandang sebagai suatu proses rehabili-tasi: norma-norma dan aturan dunia tahanan tampak terorganisir sebagai lavvan dari norma dan aturan masyarakat konvensional).

Apa yang dikemukakan oleh Clemmer ini sepertinya menjadi fakta, apabila kita melihat pangakuan seorang narapidana seperti berikut ini:

Life here becomes a dichotomy, a dichotomy between the inside and the outside. The outside is "real life", the insides unreal. But after a ehile this place gradually becomes reality and the outside becomes unreal and eventually you get lost.... I'am a twenty-seven-year-old man. I'am tried: I'm rjgtheous tired. I've been in here seven and half years now and I'am just tired to be bone of it (a black prisoner). ${ }^{3}$

(Kehidupan di sini menjadi dua bagian yang terpisahkan, dua bagian antara kehidupan di luar adalah "kehidupan yang sebenarnya": di dalam adalah semu. Tetapi setelah beberapa waktu secara berangsur-agsur kehidupan di tempat ini menjadi kenyataan dan kehidupan di luar menjadi tidak nyata. Dan akhirnya anda bingung, ... saya berusia dua puluh tujuh tahun, saya lelah, saya patut merasa lelah. Sampai saat ini telah berada di sini selama tujuh setengah tahun dan rasa lelah ini sudah mendarah daging (seorang narapidana kulit hitam).

Ternyata Clemmer membagi talianan ke dalam tiga kelompok, yaitu:

Very simply, we divided inmates in to three groups: those who had been in only a short time, those who had were near neither entry nor release. ${ }^{4}$

(Secara sederhana kita membagi tahanan/narapidana ke daiam kelompok: mereka yang nusiik dalam

3 Wrigth, Op. Cit hal. 185

4 Wheeler, Op, Cit, Socialization in Correctional, hal. 195 
waktu sebentar saja. mereka yang sebentar untuk menjalaiiinya, dan merelca yang lidak $\mathrm{p}$ eniali masuk dan juga tidak pernah bebas).

Dengnn memahami pendapat Clemmer dan pengakuan seorang narapidana kulit hitam tersebut, maka pembinaan narapidana di dalam lembaga pemasyarakatan, khususnya di Indonesia haruslah lebih diarahkan kepada kegiatan-kegiatan yang lebih bersifat memberi bekal/pengetahuan yang dapat dirasakan bukan sebagai sesuatu yang memaksa, membosankan atau bersifal indoktrinatif. Sebagaimana disadari bahwa pembinaan narapidan di dalam lembaga pemasyarakatan bertujuan antara lain adalah reintegrasi untuk mongembalikan kesatuan hubungan hidup dan kehidupan antara terpidana dengan masyarakat luas melalui pembinaan narapidana yang kolaboratif, yaitu kerjasarna antara petugas terpidana dan masyarakat untuk mengurangi keterasingan (isolasi) terpidana dengan kehidupan masyarakat luas baik dalam arti fisik maupun nilai-nilai masyarakat: ${ }^{5}$

Sehubungan dengan itu, maka guna mengefektifkan pembinaan narapidana selama menjalani huknman. Ada baiknya menyimak kursus hukum pidana seperti apa yang pernah dilakukan di Lernbaga Pemasyarakatan di Semarang oleh Fakultas Hukum Universitas Diponegoro. Tujuan diselenggarakan kursus hukum ${ }^{6}$ itu adalah sebagai berikut:

\section{Mencoba membantu memecahkan inasalah so-} sial yang dihadapi terpidana. Yang berkaitan dengan akibat terputusnya hubungan dengan keiuarga. deiigari tempat dia bekerja dan sebagainya.

2. Sebagai suatu langkah untuk mengurangi beban kejiwaan (psikologis) terpidana, dalam rangka pembinaan terpidana yang kolaboratif. Lebih jauh agar terpidana tidak merasa kehilangan status mereka baik sebagai warga masyarakat biasa rnaupun sebagai warga Indonesia.

3. Mencoba niembantu program dan kebijaksanaan lembaga pemasyarakatan dalam menyadarkan masyarakat untuk beriklitiar dalam usaha-usaha kernanusiaan dalam- rangka pengembangan terpi-

5 Thomas Sunaryo, "Perpustakaan Penjara", Majalah Bahana, Nomor 1 Tahun V, Januari-Februari 1983, hal. 26

6 "Kursus Hukum bagi terpidana dan Petugas lembaga Pemasyarakatan di Semarang", oleh FH-UNDIP, Majalah Bahana, Lk-UI No. 4/VI/1984, hal. 29 dana masyarakat, sebab itu semua hal dapat atau harus dikerjakan oleh Pemerintah.

Sebelum membahas (mengkaji) lebih lanjut akan manfaat pembinaan bagi narapidana dalam membangun sikap taat pada hukum, terlebih dahulu perlu melihat bentuk/pola pembinaan yang diterapkan bagi narapidana selama menjalani hukuman di Lembaga Pemasyarakatan, sehubungan dengan hal ini sebagai pendahuluan dapat dilihat pada Surat Keputusan Menteri Kehakiman RINomor: M.02.PK.04 10 tahun 1990 tentang pola pembinaan narapidana/tahanan. Lebih lanjut menurut SK ini yang dirnaksud dengan pembinaan narapidana dan anak didik ialah: ${ }^{7}$ semua usaha yang ditujukan untuk mempeibaiki dan meningkatkan akhlak (budi pekerti) para narapidana dan anak didik yang berada di dalam lembaga pemasyarakatan/rumah tahanan negara (intramural treatment).

Pembinaan dimulai sejak narapidana diterirna di LP (atas dasar putusan hakim yang pasti) sampai menjalani program realese baik berupa pemberian cuti menjelang lepas (pre reales treatment), rnaupun pemberian lepas bersyarat. Metode pembinaan/bimbingan meliputi: ${ }^{8}$

a. Pembinaan berupa interaksi langsung yang sifatnya kekeluargaan antara pembina dengan yang di bina (warga binaan pemasyarakatan);

b. Pembinaan bersifat persuasif yaitu berusaha merubah tingkah lakunya melalui keteladanan dan memperlakukan adil di antara sesama mereka sehingga menggugah hatinya untuk melakukan hal-hal yang terpuji; menempatkan warga binaan pemasyarakatan sebagai manusia yang memiliki potensi dan memiliki harga diri dengan hak-hak kewajiban yang sama dengan manusia lainnya:

c. Pembinaan terencana, terus meneras dan sistematis;

d. Pemeliharaan dan peningkatan langkah-langkah keamanan yang disesuaikan dengan lingkat keadaan yang dihadapi;

e. Pendekatan individual dan kelompok:

\footnotetext{
7 Pola Pembinaan Narapidana/Tahanan, Departemen Kehakiman Tahun 1990, hal. 7

8 Ibid, hal. 21
} 
f. Pembinaan kepribadian yang meliputi:

1. Pembinaan kesadaran beragama

2. Pembinaan kesadaran berbangsa dan bernegara.

3. Pembinaan kemampuan intelektual atau kecerdasan.

4. Pembinaan kesadaran hukum.

5. Pendidikan umum.

6. Pendidikan keterampilan.

7. Pembinaan mental spiritual

Dasar pembinaan sebagai warga binaan pemasyarakatan adalah Undang-Udang Dasar 1945dan standart minimum rules yang tercermin dalam sepuluh prinsip pemasyarakatan. Melihat pola pembinaan narapidana selama menjalani hukuman di lembaga pemasyarakatan, rnenurut penulis, hal itu telah menunjukkan adanya suatu usaha untuk membwa agar kelak menjadi taat pada hukum. Artinya pembinaan itu memiliki sasaran yang jelas serta memiliki nilai-nilai positif bagi pernbentukan kepribadian.

Proses penanaman nilai-rulai sosial dan hukum bagi narapidana dengan pola yang telah dikemukakan sebelumnya, dapat disejajarkan dengan kehidupan suatu keluarga. Dalam hal ini petugas pembina itu harus berperan sebagai Bapak dan Ibu bagi setiap narapidana, di mana peran sebagai orang tua haras memberikan contoh-contoh keteraturan (tata tertib) bagi seluruh anak (baik pada saat mengikuti pembinaan maupun kegiatan lainnya).

Secara tidak disadari petuah-petuah. dari petugas, baik yang bersumber dari ajaran agama maupun budaya bahkan diselang-selangi dengan penyuluhan hukum, melalui interaksi antara petugas terhadap narapidana bagi pembentukan sikap dan perilaku dilingkungannya. Tujuannya sederhana saja, yaitu: agar kelak seluruh narapidana menjadi orang yang bertanggung jawab.

Namun kendala selalu dihadapi anak (narapidana) yaitu tidak mempunyai kebebasan untuk berbuat sesuatu atau menyatakan seluruh keberadaannya, karena semua pola pembinaan telah terencana mengikuti sistem yang ada (dalam hal ini tidak ada kesempatan untuk saling tukar pikiran lebih dalam antara petugas dengan narapidana).
Dalam hal ini urgensi yang lebih jauh harus dilihat dari pembinaan narapidana (proses pemasyarakatan) itu adalah menjadikan narapidana menjadi orang yang baik, tidak melanggar hukum lagi, menjadi peserta yang kreatif dan aktif dalam pembangunan, berbahagia di dunia dan akhirat, seperti apa yang dikemukakan oleh Doktor Sahardjo.

Dan pemasyarakatan itu sendiri harus diartikan sebagai proses dimana elemen-elemen dari interaksi hidup, kehidupan dan penghidupan itu semuanya harus aktif dan positif bekerjasama timbal balik atas gotong royong demi perkembangan integritas itu ke arah yang lebih sempuma, yakni dengan lain perkataan menuju masyarakat yang adil dan makmur berdasarkan Pancasila. $^{9}$

Tujuan ini harus dipahami bahwa kebahagiaan di dunia tidak bersifat materi, tapi lebih daripada itu yaitu bagairnana ia dapat membebaskan dirinya dari belenggu- belenggu yang mengikatnya (belenggubelenggu itu sendiri dapat berupa kemalasan, rasa putus asa, hilang harapan, dan merasa terus berdosa walaupun sudah mendapat bimbingan rohani).

Pembinaan narapidana dengan seperangkat kegiatannya, (baik itu pendidikan keterampilan umum/ bertani) sebenamya merapakan suatu alat bantu yang sasarannya adalah merangsang kreatifitas dan gairah narapidana agar dapat berbuat yang berguna bagi orang banyak (khususriya untuk kepentingan lembaga), setelah hal ini dapat diresapi. maka tahap selanjutnya adalah mengembangkan atau melipat gandakan hasil kerja (meningkatkan prestasi kerja). Dengan adanya gairah kerja dan berprestasi maka hal ini akan mempengaruhi rasa percaya diri. Dengan adanya gairah kerja dan berprestasi maka hal ini telah mampu mengalahkan segala belenggu dan mulai menatap hari esok yang lebih cerah dan dengan itu pula terpatri suatu tekad agar tetap bergiat, melatih diri untuk mengalahkan diri sendiri dan menerima keberadaan diri sendiri dan rnengembangkan suatu sikap mau menerima bimbingan dan didikan ke tahap yang lebih baik dan sempurna yaitu berupa kesadaran bahwa dirinya adalah seorang narapidana yang masih

\footnotetext{
9 Baharuddin Suryobroto, Functie Pemasyarakatan dalam Negara Pancasila, Lembaga Pemasyarakatan Khusus Dewasa Muda Sukamiskin, 1967, hal. 13
} 
harus menjalani hukuman. Penerimaan diri berupa seorang narapidana akan berdampak positif berupa adanya suatu kesadaran bahwa di balik kehidupan di dalam lembaga pemasyarakatan ada dunia (masyarakat bebas) vang setiap orang bisa menikmatinya.

Munculnya kesadaran berupa keinginan hidup di dalam alam bebas yang dapat bertemu dengan sanak keluarga dan ingin membuktikan kepada masyarakat bahwa dirinya telah sadar dan tobat menunjukkan adanya suatu pemahaman pada diri narapidana bahwa ketaatan (sikap patuh) terhadap segala hal yang berbau ketertiban harus dijalani.

Dengan adanya keinginan untuk bermasyarakat, walau memerlukan kedisiplinan, narapidana akan bermasyarakat dan mentaati hokum yang berlaku. Hal ini cukup beralasan, di mana narapidana selama berada di lembaga pemasyarakatan bukan hanya mendapat pembinaan mental, tapi juga pembinaan keterampilan. Sedangkan tujuan pembinaan keterampilan itu sendiri, adalah untuk membentuk manusia narapidana yang setelah bebas akan imenjadi manusia yang mandiri, yakni manusia yang akan mendapatkan lapangan kerja yang sesuai dengan keterampilan yang mereka peroleh selama di lembaga pemasyarakatan. ${ }^{10}$

Pengertian mendapatkan lapangan kerja di sini ialah pertama-tama adalah manusia yang dapat menciptakan kerja secara mandiri dan manusia yang siap untuk mengisi lowongan pekerjaan sesuai dengan keahliannya. ${ }^{11}$

Memahami tujuan pembinaan keterampilan, maka salah satu indikator keberhasilan pembinaan narapidana adalah narapidana tersebut dapat bekerja di rnasyarakat kelak. Bekerjanya narapidana di masyarakat merupakan wujud nyata dari keberhasilan pembinaan.

Tetapi, pernahkah ditanyakan bahwa apabila narapidana gagal mentaati hokum, apakah juga dapat dikatakan sebagai kegagalan dalam pembinaan? Untuk menjawab hal ini memang tidak bisa dilepaskan dari aktivitas narapidana setelah berada di masyarakat. Bekerjanya bekas narapidana di masyarakat begitu

10 Thaher Abdullah, "Pelaksanaan Pembinaan Ketrampilan Narapidana, sebagai Bekal Reintegrasi dalam Masyarakat”, Majalah, Lembaga Pemasyarakatan kelas I Cirebon, 1984, hal. 1

11 Ibid, hal. 1 juga halnya dengan ketaatannya pada hukum akan menonjol. Mengapa dikatakan demikian, hal ini semata-mata ingin rnembuktikan bahwa sulit untuk tidak melanggar hukum kalau kegiatan (pekerjaan) tidak ada, jadi semakin jelas bagi kita bagaimana sebenarnya keterkaitan ketaatan hukum terhadap bekerja tidaknya bekas narapidana.

Selama bekas narapidana itu tidak memiliki pekerjaan dan tidak diterima di masyarakat atau dicurigai maka seketika itu juga keinginan-keinginan (godaangodaan) akan mengikuti kelompoknya. Oleh karena itu, sesuatu yang mustahil kalau dikatakan

narapidana akan taat pada hukum walaupun tidak bekerja. Dimilikinya pekerjaan oleh seorang bekas narapidana di masyarakat memungkinkan ia dapat melakukan kegiatan sosial. Dengan berinteraksinya bekas narapidana ke dalam masyarakac aktif, menunjukkan adanya usaha menyesuaikan diri terhadap kehidupan masyarakat teratur, di mana norma-norma kesusilaan dan hukum ditaati.

Terciptanya (terdapatnya) pembinaan yang efektif, artinya pola pembinaan yang diprogramkan dapat berjalan sesuai dengan prinsip-prinsip pemasyarakatan maka hal itu akan menjadi salah satu upaya rnencegah prisonisasi. Adapun yang dimaksud dengan prisonisasi ialah istilah yang digunakan oleh T.P. Morris dalam bukunva yang berjudui "Pentoville" (1963) untuk menggambarkan tingkah laku nyata narapidana yang bertujuan untuk menyesuaikan diri dengan kehidupan penjara. Tampaknya tingkah laku mereka sesuai dengan aturan-aturan yang ada, namun mereka sebenarnya menolak untuk mentaati aturan-aturan itu. ${ }^{12}$

\footnotetext{
12 Soerjono Soekanto dan Pudji Santoso, Kamus Kriminologi, Jakarta: Ghalia Indonesia, 1985, hal. 77
} 


\section{Daftar Pustaka}

Eric Olin Wright, The Meaning of Prison in the livers of prison, dalam Criminal Justice Allies and Adversaries, John R. Snortum/Illaiia Hader, palisades publisher. 1978

Staton Wheeler, "Socialization in Correctional Institutions" dalam "Crime and Justice, edited by Sir Leon Randzinovics and Marvin E Wolfgang, New York: Basic Books, Inc, Publisher, 1969, Volume II.

Thomas Sunaryo, "Perpustakaan Penjara", Majalah Bahana, Nomor 1 Tahun V, JanuariFebruari 1983.

Kursus Hukum bagi terpidana dan Petugas lembaga Pemasyarakatan di Semarang", oleh FH-UNDIP, Majalah Bahana, Lk-UI No. 4/ VI/1984.

Pola Pembinaan Narapidana/Tahanan, Departemen Kehakiman Tahun 1990.

Baharuddin Suryobroto, Functie Pemasyarakatan dalam Negara Pancasila, Lembaga Pemasyarakatan Khusus Dewasa Muda Sukamiskin, 1967.

Thaher Abdullah, "Pelaksanaan Pembinaan Ketrampilan Narapidana, sebagai Bekal Reintegrasi dalam Masyarakat”, Majalah, Lembaga Pemasyarakatan kelas I Cirebon, 1984.

Soerjono Soekanto dan Pudji Santoso, Kamus Kriminologi, Jakarta: Ghalia Indonesia, 1985. 